\title{
Prognostic significance of synergistic hexokinase-2 and beta2-adrenergic receptor expression in human hepatocelluar carcinoma after curative resection
}

\author{
Zhi-Feng Zhang ${ }^{1 \dagger}$, Xiao-Sha Feng ${ }^{1 \dagger}$, He Chen ${ }^{1 \dagger}$, Zhi-Jun Duan $^{1 *}$, Li-Xia Wang ${ }^{1}$, Dong Yang ${ }^{1}$, Pi-Xu Liu ${ }^{2}$, \\ Qiu-Ping Zhang ${ }^{3}$, Yan-Ling Jin ${ }^{3}$, Zhi-Gang Sun ${ }^{3}$ and Han Liu ${ }^{2}$
}

\begin{abstract}
Background: Hexokinase-2 (HK2) and Beta2-adrenergic receptor (Beta2AR) are overexpressed in hepatocellular carcinoma (HCC) tissues and associated with poor prognosis. However, the synergistic effect of HK2 and Beta2AR in HCC prognosis is not elucidated. The present study aims to investigate the association between HK2 and Beta2AR expressions in HCC tissues, and to evaluate the synergistic effect of HK2 and Beta2AR in HCC prognosis.

Methods: Immunohistochemistry of HK2 and Beta2AR was performed on 155 paraffin embedded HCC samples retrieved from the archives of pathology department. Corresponding clinical data and prognostic data were collected through searching medical record systems, death registration systems and interviews with patient families. Spearman correlation test was performed to evaluate the association between HK2 and Beta2AR expression. Kaplan-Meier survival curves and Cox regressions were employed to evaluate HK2 and Beta2AR expression in HCC prognosis, respectively and synergistically.

Results: 109 of 155 HCC patients reached the death point, the survival time of HCC patients was $46.23 \pm 31$. 01 months after curative surgical resections of HCC. Kaplan-Meier survival analysis showed that large tumor size (more than $5 \mathrm{~cm}$ ) (hazard ratio $(\mathrm{HR})=8.42,95 \%$ confidence interval $(\mathrm{Cl})=3.81-18.59, P<0.0001$ ), advanced TNM stage (III and IV stages) ( $H R=2.09,95 \% \mathrm{Cl}=1.21-3.62, P<0.001)$ and AFP more than $20 \mu \mathrm{g} / \mathrm{L}$ $(\mathrm{HR}=1.49,95 \% \mathrm{Cl}=1.02-2.18, P=0.0302)$ were predictors for poor prognosis. HK2 and Beta2AR positive expression was detected in 66 (42.58) and 122 (78.71\%) HCC samples respectively. In univariate analysis, HK2(+) $(H R=2.70,95 \% \mathrm{Cl}=1.76-4.15, P<0.0001)$ and Beta2AR(+) $(\mathrm{HR}=4.61,96 \% \mathrm{Cl}=3.14-6.76, P<0.0001)$ were associated with poor prognosis. In multivariate analysis, HK2 $(+)(P<0.0001)$ and Beta2AR(+) $(P<0.0001)$ were also associated with poor prognosis. HK2(+)/Beta2AR(+) in HCC samples had poorer prognosis compared with HK2(-)/Beta2AR(-) in both univariate analysis $(H R=4.69,95 \% \mathrm{Cl}=2.91-7.57, P<0.0001)$ and multivariate analysis $(P<0.0001)$. HK2 $(+) /$ Beta2AR(+) in HCC samples had poorer prognosis compared with HK2(-)/Beta2AR(+) in both univariate analysis $(H R=1.76,95 \% \mathrm{Cl}=1.17-2.64, P=0.003)$ and multivariate analysis $(P=0.004)$.

(Continued on next page)
\end{abstract}

\footnotetext{
* Correspondence: cathydoctor@sina.com

${ }^{\dagger}$ Equal contributors

'Department of Gastroenterology, The First Affiliated Hospital of Dalian

Medical University, 116000 Dalian, Liaoning Province, China

Full list of author information is available at the end of the article
} 
(Continued from previous page)

Conclusion: HK2 and Beta2AR play important roles in HCC progression. HK2 and Beta2AR expression in HCC is correlated positively. Beta2AR may increase HCC invasion and metastasis in collaboration with HK2. HK2 and Beta2AR can predict HCC prognosis both independently and synergistically.

Keywords: Hepatocellular carcinoma, Hexokinase-2, Beta2-adrenergic receptor, Prognosis, Immunohistochemistry

\section{Background}

Hepatocellular carcinoma (HCC) is the fifth most common cancer in men and seventh most common cancer in women worldwide [1]. HCC is also the third most common cause of death from carcinomas worldwide [1, 2]. Although new treatment modalities for HCC have been developed in recent years, improvement of the five-year survival rates mainly relies on diagnosis at early stages of HCC. Early stage HCC can be treated with curative surgical resections, radiofrequency ablation, percutaneous ethanol injection and transarterial chemoembolization [2]. Moreover, only curative surgical resection has the possibility to cure HCC. As for the advanced stage HCC, although tyrosine kinase inhibitors, such as Sorafenib and Linifanib have been developed to improve survival rates, the cure of advanced stage HCC is rarely achieved [3, 4]. Therefore, how to choose the optimal therapy for the individual patient in order to maximize the survival time is of great importance to both clinicians and patients. Another issue of importance to clinicians and patients is to predict prognosis of $\mathrm{HCC}$ especially for the patients underwent curative $\mathrm{HCC}$ resections and for the patients with advanced stage HCC. Proper prediction of prognosis can guide clinicians to choose the right therapies and help patients to arrange the remaining life appropriately. To date, no individual biomarker can predict prognosis of HCC accurately. The combination of two or more correlated biomarkers for HCC prognosis may improve the power of prognosis predictions of $\mathrm{HCC}$.

Beta2-adrenergic receptor (Beta2AR) is a transmembrane $G$ protein-coupled receptor (GPCR), which can regulate cell proliferation via cyclic adenosine monophosphate and protein kinase A pathways [5]. Beta2AR are overexpressed in multiple cancers especially in gastrointestinal cancers and $\mathrm{HCC}$ [6-8]. It has been proved that Beta2AR agonist can promote DNA synthesis and beta-blockers can block DNA synthesis in pancreatic ductal carcinoma cell lines [7]. Selective Beta2AR blockage can also suppress colorectal cancer growth via EGFR-Akt/ ERK signaling, G1-phase arrest and apoptosis [9]. Through increasing DNA synthesis, accelerating cell cycle and decreasing apoptosis, activation of Beta2AR promotes cancer growth, invasion and metastasis. High expression of Beta2AR may play a role in the canceration of injured hepatocytes, and may represent high grade of malignancy of HCC. So high expression of Beta2AR in HCC tissues is proposed be a biomarker for poor prognosis, which is supported by a previous survival study of HCC with immunohistochemistry [10].

Besides increased DNA synthesis, accelerated cell cycle and decreased apoptosis, another feature of cancer is the energy shift to aerobic glycolysis called Warburg effect, even in adequate oxygen environments [11]. Accelerated aerobic glycolysis is of importance to cancer cell survival, growth and metastasis [11]. Hexokinase $(\mathrm{HK})$ is a key enzyme in glycolysis, to date, four HK isoforms were identified in mammals [12]. It is shown that HK2 is overexpressed in HCC tissues [13, 14]. Overexpression of HK2 may also represent high grade of malignancy. Two survival studies proved this hypothesis, and showed that high level expression of $\mathrm{HK} 2$ was an independent poor prognostic biomarker for HCC $[13,14]$.

Moreover, HK2 and Beta2AR are not independent, they are related in $\mathrm{HCC}$ development. Recently, one study indicates that activation of Beta2AR can promote HK2 expression, and inhibition of Beta2AR can decrease HK2 expressions in breast cancer cell lines [15]. It is deduced that Beta2AR might increase the grade of malignancy of cancers via promoting HK2 expression. However, the relationship between Beta2AR and HK2 expression in HCC tissues is not fully elucidated. We postulate that Beta2AR and HK2 expression in HCC tissues correlates positively; overexpression of $\mathrm{HK} 2$ and beta2AR in $\mathrm{HCC}$ can predict prognosis of $\mathrm{HCC}$ patients synergistically; Beta2AR may increase the grade of malignancy of $\mathrm{HCC}$ via promoting $\mathrm{HK} 2$ expression. In the current study, we performed immunohistochemistry assays to prove the above hypotheses.

\section{Methods}

\section{HCC patients and tissue samples}

This study is a retrospective study. $160 \mathrm{HCC}$ patients underwent curative resections between January 2000 and December 2013 in the First affiliated hospital of Dalian Medical University were included in our study. Surgical 
treatment selection was mainly based on the Barcelona Clinic Liver Cancer (BCLC) algorithm [16]. Moreover, ten HCC patients with regional metastasis underwent HCC resections and lymph node dissections were also included into our study. Paraffin embedded pathologic samples were retrieved from the archives of the Department of Pathology. All the tissue sections were evaluated by experienced pathologist to confirm the diagnosis of HCC. Cholangiocellular carcinoma and other carcinomas of the liver were excluded during pathology evaluation. HCC patients accompanied with other site carcinomas were also excluded from our study. Because Beta2AR and HK2 were associated with metabolism, HCC patients accompanied with metabolic diseases including diabetes mellitus and thyroid diseases were also excluded from our study. This study was approved by Medical Ethics Committee of First Affiliated Hospital of Dalian Medical University. Consent was obtained from all participants (alive HCC patients or relatives of deceased HCC patients).

\section{Survival data and clinical data collection}

Clinical and laboratory data of each included patient during the hospital stay for curative resection were retrieved from the medical record system of the First Affiliated Hospital of Dalian Medical University. The computed tomography (CT) scanning and magnetic resonance images (MRI) of each patient were collected via Picture Archiving and Communication Systems. The records of operational procedures and observations during operations were also collected via medical record system. The CT images, MRI images and observations during operation were used to evaluate the tumor size (maximum diameter of the tumor). The survival data and the death date of each patient were retrieved through telephone interviews with patient families, and confirmed by searching the municipal death registration system of Dalian (the final collection date was 20th March 2014, the data collection period was limited in two weeks). Overall survival was used to evaluate HCC patient survival after surgical curative resections. Paraffin embedded pathologic samples of each patient were reevaluated by experienced pathologist to determine the differentiation grade of HCC according to Edmondson-Steiner histopathologic grading [17]. The HCC staging evaluation before operation was based on American Joint Commission on Cancer 7th edition TNM system [18].

\section{Immunohistochemistry and density scoring}

Immunohistochemistry was performed with the MaxVisionTM AP kit (Fuzhou Maixin Biotech. Co., Ltd, Fuzhou, China) according to the manufacture manuals. HK2 expression was evaluated with a rabbit anti-human HK2 monoclonal antibody (Cell Signaling Technology, Inc., Danvers, MA, USA) in accordance with the manufacturer's protocol with antibody dilution of 1:50. Beta2AR was evaluated using a rabbit anti-human Beta2AR monoclonal antibody (Abcam, Cambridge, MA, USA) in accordance with the manufacturer's protocol with antibody dilution of 1:50. Both the intensity and proportion of stained cells in a HCC section $(200 \times)$ were inspected and evaluated. Staining intensity was classified with a four grade system: no staining (0), weak (1), moderate (2), strong (3). The percentage of positive stained cells was also classified into a four scale system: $<5 \%$ (0), 5-25\% (1), 26-50\% (2), >50\% (3). All the scores were based on the mean scores of ten randomly selected fields of tissue sections. The staining intensity score plus the percentage score made the final score of each sample (the final score ranged from 0 to 6 ). If the final score is more than 3, the sample was determined to be positive. Otherwise, the sample was determined to be negative.

\section{Statistical analysis}

Pearson Chi-square test was used to analyze the associations between protein expression and clinical data. Survival time was shown as mean and standard deviation (SD). One-way ANOVA analysis and least significant difference (LSD) test were employed to determine the difference of live time among different groups. Spearman correlation test was performed to evaluate the association between HK2 and beta2AR expression with the final scores. KaplanMeier survival curve was employed to evaluate HK2 expression, Beta2AR expression and clinical data in HCC prognosis, respectively and synergistically. Cox regression analysis was also performed for multivariate analyses (all the selected clinical data was included in Cox regression) for HK2, Beta2AR and clinical data in HCC prognosis. $P<$ 0.05 was considered statistically significant. Pearson Chisquare test and One-way ANOVA analysis were performed with the SPSS16.0 statistical software package (SPSS Inc., Chicago, IL, USA). Survival analysis and Cox regression analysis were performed with MedCalc 11.4.2.0 (MedCalc Software bvba, Acacialaan, Ostend, Belgium). Survival curve, Cox regression curve, Spearman correlation diagram and One-way ANOVA diagram were depicted with MedCalc 11.4.2.0 (MedCalc Software bvba, Acacialaan, Ostend, Belgium).

\section{Results}

The association between clinical data and survival

160 paraffin embedded HCC samples were retrieved from the archives of pathology department. Complete clinical data and prognostic data were collected through searching medical record systems and taking interviews with patient families. The survival data were confirmed by searching municipal death registration system of $\mathrm{Da}$ lian. Survival information of 155 patients was retrieved successfully, the rate of lost to follow-up was $3.13 \% .155$ patients were included into final analyses. 109 (70.32 \%) 

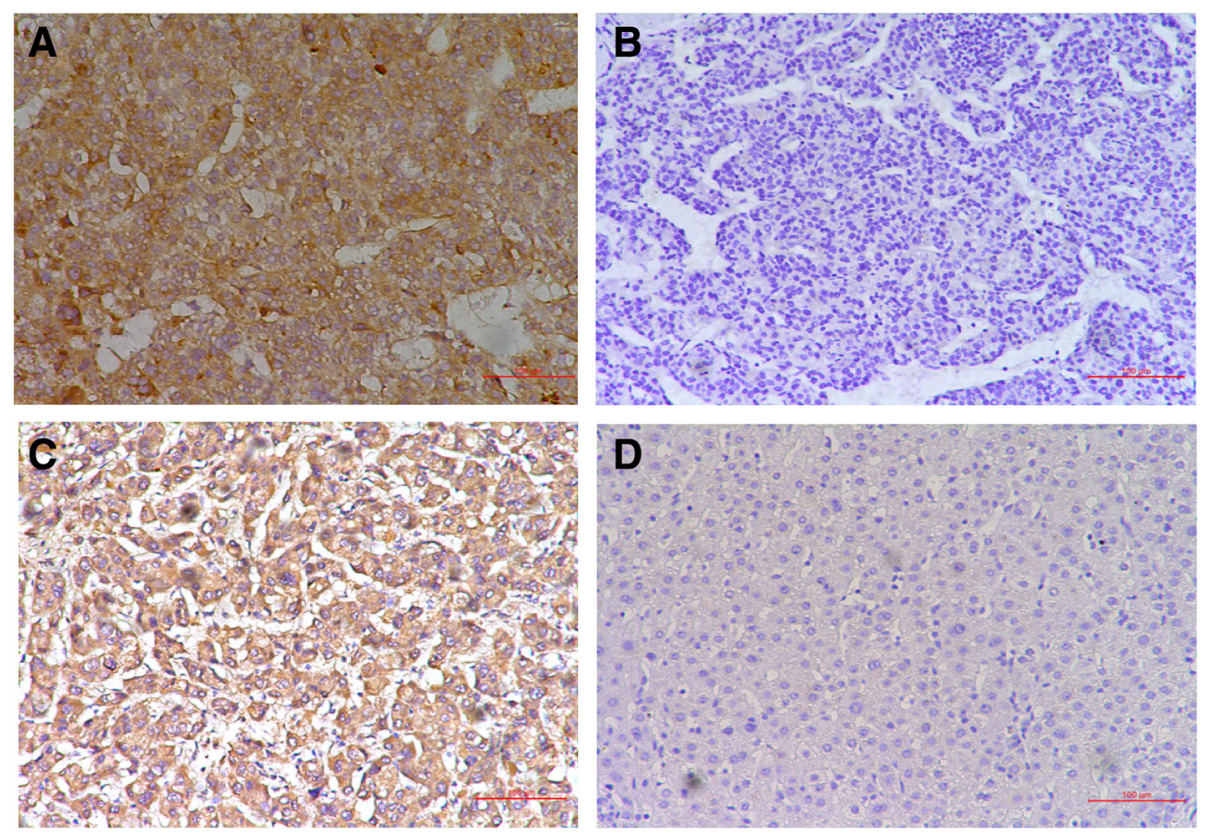

Fig. 1 Immunochemistry of HCC tissues. a Representative positive staining of HK2 in HCC tissues. b Representative negative staining of HK2 in HCC tissues. c Representative positive staining of Beta2AR in HCC tissues. d Representative negative staining of Beta2AR in HCC tissues

HCC patients reached the death point, the survival time of HCC patients was $46.23 \pm 31.01$ months after curative surgical resections of HCC. Kaplan-Meier survival analysis showed that large tumor size (more than $5 \mathrm{~cm}$ ) (hazard ratio $(\mathrm{HR})=8.42,95 \%$ confidence interval $(\mathrm{CI})$ $=3.81-18.59, P<0.0001)$, advanced TNM stage (III and IV stages $)(\mathrm{HR}=2.09,95 \% \mathrm{CI}=1.21-3.62, P<0.001)$ and AFP more than $20 \mathrm{ug} / \mathrm{L}(\mathrm{HR}=1.49,95 \% \mathrm{CI}=1.02-2.18$, $P=0.0302$ ) were predictors for poor prognosis. Age, gender, Hepatitis viral infection, tumor number, tumor differentiation grade and post operational treatment are not associated with prognosis of HCC patients. Cox regression showed that only large tumor size and advanced TNM stage were associated with poor prognosis of HCC patients.

HK2 and Beta2AR are over expressed in HCC

Positive staining of HK2 was detected in the cytoplasm of HCC tissues. And positive staining of Beta2AR was also detected in the membrane and cytoplasm of HCC

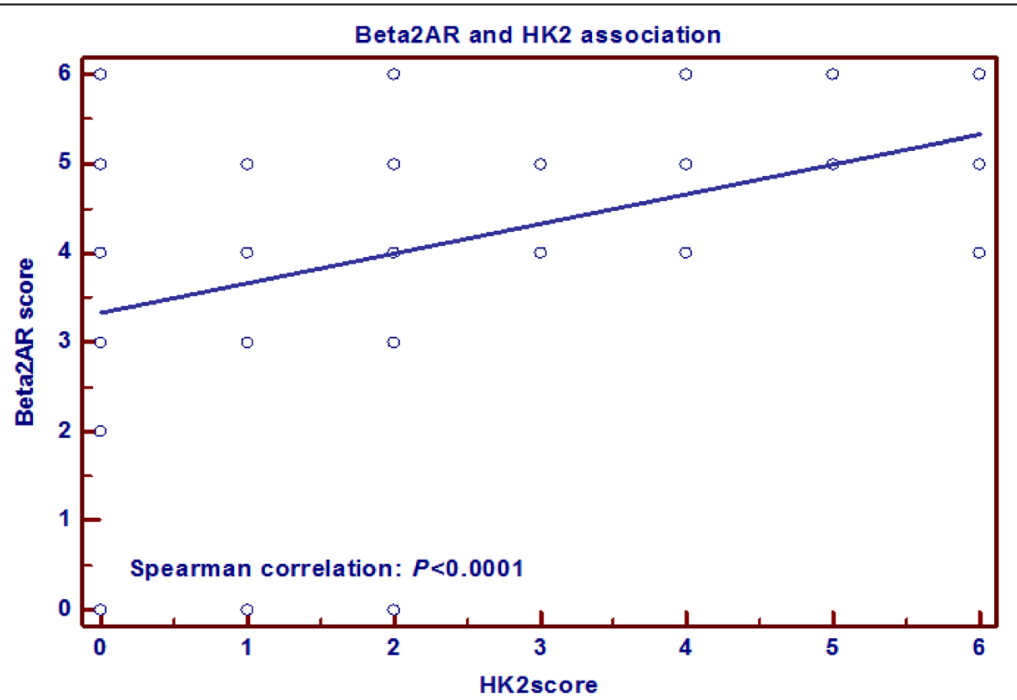

Fig. 2 Spearman correlation between HK2 and Beta2AR. Spearman correlation test shows that HK2 and Beta2AR expression is correlated positively $(P<0.0001)$ 
Table 1 The details of association between Beta2AR expression and clinical data

\begin{tabular}{|c|c|c|c|}
\hline & Beta2AR positive & Beta2AR negative & $P$ value \\
\hline \multicolumn{4}{|l|}{ Age } \\
\hline$\leq 50$ year & 35 & 7 & 0.391 \\
\hline$>50$ year & 87 & 26 & \\
\hline Gender & & & 0.848 \\
\hline Male & 98 & 27 & \\
\hline Female & 24 & 6 & \\
\hline Hepatitis virus infection & & & 0.439 \\
\hline HBV & 106 & 29 & \\
\hline $\mathrm{HCV}$ & 4 & 2 & \\
\hline $\mathrm{HBV}+\mathrm{HCV}$ & 1 & 1 & \\
\hline None & 11 & 1 & \\
\hline AFP level & & & 0.685 \\
\hline$\leq 20 \mathrm{ug} / \mathrm{L}$ & 58 & 17 & \\
\hline$>20 u g / L$ & 64 & 16 & \\
\hline Tumor number & & & 0.154 \\
\hline Solitary & 118 & 30 & \\
\hline Multiple & 4 & 3 & \\
\hline Tumor size & & & 0.0001 \\
\hline$\leq 5 \mathrm{~cm}$ & 82 & 33 & \\
\hline$>5 \mathrm{~cm}$ & 40 & 0 & \\
\hline TNM stage & & & 0.795 \\
\hline । & 44 & 12 & \\
\hline$\|$ & 49 & 14 & \\
\hline III & 22 & 4 & \\
\hline IV & 7 & 3 & \\
\hline Differentiation & & & 0.328 \\
\hline Well & 36 & 14 & \\
\hline Moderate & 58 & 14 & \\
\hline Poor & 28 & 5 & \\
\hline Post operation treatment & & & 0.483 \\
\hline None & 77 & 23 & \\
\hline TACE & 45 & 10 & \\
\hline
\end{tabular}

tissues. Representative positive staining and negative staining of $\mathrm{HK} 2$ and Beta2AR in $\mathrm{HCC}$ tissues are shown in Fig. 1. According to the scores of staining, $\mathrm{HK} 2$ and Beta2AR positive expression was detected in 66 (42.58) and 122 (78.71 \%) HCC samples, respectively. Spearman correlation test showed that $\mathrm{HK} 2$ and Beta2AR expression was correlated positively $(P<0.0001)$, as shown in Fig. 2 .

\section{The association between HK2/Beta2AR expression and clinical data}

There was no significant difference between HK2 positive staining samples and HK2 negative staining samples in age,
Table 2 The details of association between HK2 expression and clinical data

\begin{tabular}{|c|c|c|c|}
\hline & HK2 positive & HK2 negative & $P$ value \\
\hline \multicolumn{4}{|l|}{ Age } \\
\hline$\leq 50$ year & 23 & 19 & 0.062 \\
\hline$>50$ year & 43 & 70 & \\
\hline Gender & & & 0.360 \\
\hline Male & 51 & 74 & \\
\hline Female & 15 & 15 & \\
\hline Hepatitis virus infection & & & 0.594 \\
\hline HBV & 57 & 78 & \\
\hline $\mathrm{HCV}$ & 3 & 3 & \\
\hline $\mathrm{HBV}+\mathrm{HCV}$ & 0 & 2 & \\
\hline None & 6 & 6 & \\
\hline AFP level & & & 0.054 \\
\hline$\leq 20 \mathrm{ug} / \mathrm{L}$ & 26 & 49 & \\
\hline$>20 \mathrm{ug} / \mathrm{L}$ & 40 & 40 & \\
\hline Tumor number & & & 0.121 \\
\hline Solitary & 65 & 83 & \\
\hline Multiple & 1 & 6 & \\
\hline Tumor size & & & 0.001 \\
\hline$\leq 5 \mathrm{~cm}$ & 40 & 75 & \\
\hline$>5 \mathrm{~cm}$ & 26 & 14 & \\
\hline TNM stage & & & 0.015 \\
\hline । & 26 & 30 & \\
\hline$\|$ & 18 & 45 & \\
\hline III & 16 & 10 & \\
\hline IV & 6 & 4 & \\
\hline Differentiation & & & 0.145 \\
\hline Well & 19 & 31 & \\
\hline Moderate & 28 & 44 & \\
\hline Poor & 19 & 14 & \\
\hline Post operation treatment & & & 0.630 \\
\hline None & 44 & 56 & \\
\hline TACE & 22 & 33 & \\
\hline
\end{tabular}

gender, Hepatitis viral infection, AFP level, tumor number, tumor differentiation grade and post operational treatment. Only large tumor size and advanced TNM stage were correlated with $\mathrm{HK} 2$ positive staining positively. There was also no significant difference between Beta2AR positive staining samples and Beta2AR negative staining samples in age, gender, Hepatitis viral infection, AFP level, tumor number, TNM stage, tumor differentiation grade and post operational treatment. Only large tumor size was correlated with Beta2AR positive staining positively. The details of the association tests between HK2/Beta2AR expression and clinical data are shown in Tables 1 and 2 . 
Table 3 The details of association between HK2 expression and clinical data in Beta2AR positive samples

\begin{tabular}{|c|c|c|c|}
\hline & Beta2AR posit & & \\
\hline & HK2 positive & $\overline{\text { HK2 negative }}$ & $P$ value \\
\hline$\overline{\text { Age }}$ & & & \\
\hline$\leq 50$ year & 23 & 12 & 0.102 \\
\hline$>50$ year & 43 & 44 & \\
\hline Gender & & & 0.357 \\
\hline Male & 51 & 47 & \\
\hline Female & 15 & 9 & \\
\hline Hepatitis virus infection & & & 0.596 \\
\hline HBV & 57 & 49 & \\
\hline $\mathrm{HCV}$ & 3 & 1 & \\
\hline $\mathrm{HBV}+\mathrm{HCV}$ & 0 & 1 & \\
\hline None & 6 & 5 & \\
\hline AFP level & & & 0.050 \\
\hline$\leq 20 \mathrm{ug} / \mathrm{L}$ & 26 & 32 & \\
\hline$>20 \mathrm{ug} / \mathrm{L}$ & 40 & 24 & \\
\hline Tumor number & & & 0.235 \\
\hline Solitary & 65 & 53 & \\
\hline Multiple & 1 & 3 & \\
\hline Tumor size & & & 0.091 \\
\hline$\leq 5 \mathrm{~cm}$ & 40 & 42 & \\
\hline$>5 \mathrm{~cm}$ & 26 & 14 & \\
\hline TNM stage & & & 0.006 \\
\hline । & 26 & 18 & \\
\hline$\|$ & 18 & 31 & \\
\hline III & 16 & 6 & \\
\hline IV & 6 & 1 & \\
\hline Differentiation & & & 0.229 \\
\hline Well & 19 & 17 & \\
\hline Moderate & 28 & 30 & \\
\hline Poor & 19 & 9 & \\
\hline Post operation treatment & & & 0.377 \\
\hline None & 44 & 33 & \\
\hline TACE & 22 & 23 & \\
\hline
\end{tabular}

HK2 and Beta2AR can predict HCC prognosis independently and synergistically

Positive Beta2AR staining was observed in all HK2 positive HCC samples. Moreover, when Beta2AR was negative in the HCC tissues, HK2 was also negative in the corresponding samples. In the Beta2AR positive staining $\mathrm{HCC}$ tissues, there was no significant difference between HK2 positive samples and HK2 negative ones in age, gender, Hepatitis viral infection, AFP level, tumor number, tumor differentiation grade and post operational treatment. Only advanced TNM stage was correlated with $\mathrm{HK} 2$ positive staining. The details of the association tests between HK2 expression and clinical data in Beta2AR positive samples are shown in Table 3.

In univariate analysis, $\mathrm{HK} 2(+)(\mathrm{HR}=2.70,95 \% \mathrm{CI}=$ 1.76-4.15, $P<0.0001)$ and Beta2AR $(+)(\mathrm{HR}=4.61,96 \% \mathrm{CI}$ $=3.14-6.76, P<0.0001)$ were associated with poor prognosis. In multivariate analysis, $\mathrm{HK} 2(+)(P<0.0001)$ and Beta2AR $(+)(P<0.0001)$ were also associated with poor prognosis. $\mathrm{HK} 2(+) /$ Beta2 $\mathrm{AR}(+)$ in $\mathrm{HCC}$ samples had poorer prognosis as compared with $\mathrm{HK} 2(-) / \operatorname{Beta} 2 \mathrm{AR}(-)$ in both univariate analysis $(\mathrm{HR}=4.69,95 \% \mathrm{CI}=2.91-7.57$, $P<0.0001)$ and multivariate analysis $(P<0.0001)$. HK2 $(+) /$ Beta2AR(+) in HCC samples had the poorer prognosis as compared with $\mathrm{HK} 2(-) / \operatorname{Beta} 2 \mathrm{AR}(+)$ in both univariate analysis $(\mathrm{HR}=1.76,95 \% \mathrm{CI}=1.17-2.64, P=0.003)$ and multivariate analysis $(P=0.004)$. The survival analysis curves are shown in Fig. 3.

Regarding patients that reached death point, one-way ANOVA analysis showed that survival time of $\mathrm{HK} 2(-) /$ Beta2AR(-) patients $(106.29 \pm 26.68$ months $)$ was longer than that of $\mathrm{HK} 2(-) / \operatorname{Beta} 2 \mathrm{AR}(+)$ patients $(45.61 \pm$ 19.12 months $)(P<0.0001)$ and $\mathrm{HK} 2(+) / \operatorname{Beta} 2 \mathrm{AR}(+)$ patients $(31.13 \pm 18.00$ months $)(P<0.0001)$ significantly. The survival time of $\mathrm{HK} 2(-) / \operatorname{Beta} 2 \mathrm{AR}(+)$ patients was also longer than that of $\mathrm{HK} 2(+) / \operatorname{Beta} 2 \mathrm{AR}(+)$ patients $(P=0.001)$. The details of one-way ANOVA analysis are shown in Fig. 4.

\section{Discussion}

$\mathrm{HCC}$ is the third most common cause of death from carcinomas worldwide [1, 2]. Moreover HCC is also one of the main causes of death of liver cirrhosis irrespective of cirrhotic etiology [19]. Due to the increasing incidence of hepatitis $\mathrm{C}$ virus (HCV) infections and non-alcoholic fatty liver disease (NAFLD), the incidence of HCC in USA has doubled in the past twenty years. Based on the trend of HCC incidence, it is postulated that HCC is likely to replace breast cancer and colorectal cancer to become the third cause of death from carcinomas in USA [20]. Different from developed countries, the etiology of HCC in developing countries especially southeastern Asian countries is hepatitis B virus (HBV) infection [21, 22]. The high incidence of HBV infection also makes HCC to be a big healthy problem in southeastern Asian countries. Irrespective of the etiology of $\mathrm{HCC}$, the prognosis of $\mathrm{HCC}$ mainly relies on diagnosis at early stage and the possibility of curative surgical resections. However, even in USA, the rate of HCC diagnosed at early stage is only $46 \%$ [20]. And only a small portion of HCC patients diagnosed at early stage can receive curative resections [20]. In the developing countries, the rates of $\mathrm{HCC}$ diagnosed at early stage and the portions of HCC patients at early stage received curative resections are very low. Although tyrosine kinase 

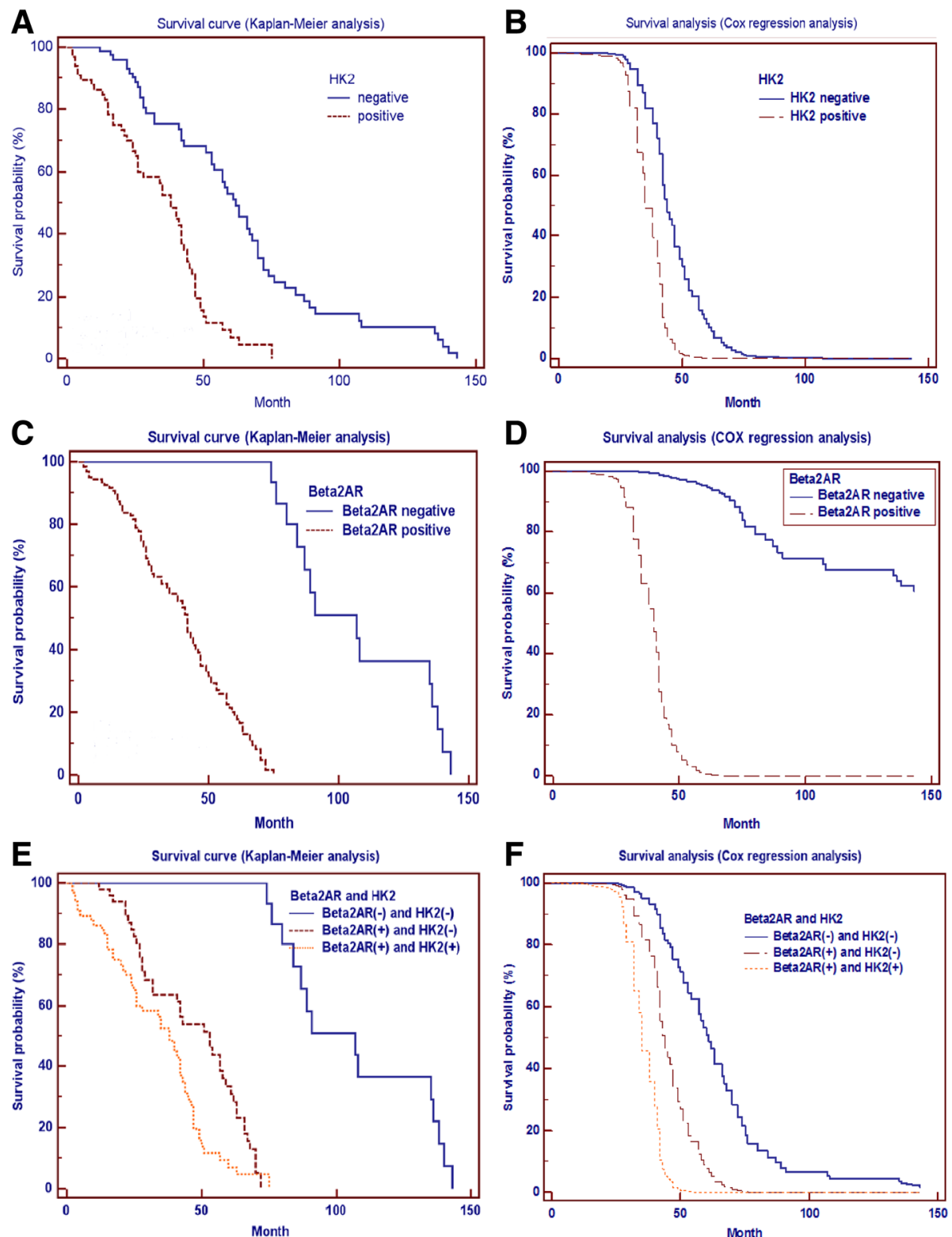

Fig. 3 Survival curve. $\mathbf{a}$ and $\mathbf{b} \mathrm{HK} 2(+)$ is associated with poor prognosis in both univariate analysis $(\mathrm{HR}=2.70,95 \% \mathrm{Cl}=1.76-4.15, P<0.0001)$ and multivariate analysis $(P<0.0001)$. $\mathbf{c}$ and $\mathbf{d}$ Beta2AR(+) is associated with poor prognosis in both univariate analysis $(\mathrm{HR}=4.61,96 \% \mathrm{Cl}=3.14-6.76$, $P<0.0001)$ and multivariate analysis $(P<0.0001)$. e and $\mathbf{f} \mathrm{HK} 2(+) /$ Beta2AR(+) in HCC samples shows poorer prognosis as compared with HK2(-)/ Beta2AR( $(-)$ in both univariate analysis $(\mathrm{HR}=4.69,95 \% \mathrm{Cl}=2.91-7.57, P<0.0001)$ and multivariate analysis $(P<0.0001)$. HK2 $(+) / \mathrm{Beta2AR}(+)$ in $\mathrm{HCC}$ samples shows poorer prognosis as compared with HK2(-)/Beta2AR(+) in both univariate analysis $(\mathrm{HR}=1.76,95 \% \mathrm{Cl}=1.17-2.64, P=0.003)$ and multivariate analysis $(P=0.004)$

inhibitors (such as Sorafeniband Linifanib) have been developed to treat HCC at advanced stage, the outcome of treatment at advanced stage is not satisfactory $[3,4]$. Scientists are still searching for new HCC treatment targets. Exploring the mechanism of HCC development may shed light on developing new therapies. Another realistic issue of importance to clinicians and patients is to predict prognosis of HCC. Proper prediction of prognosis can guide clinicians to choose the right therapies and help patients to arrange the remaining life appropriately.

Beta2AR regulates cell proliferation via cyclic adenosine monophosphate and protein kinase A pathways [5]. Through increasing DNA synthesis, accelerating cell cycle and decreasing apoptosis, activation of Beta2AR promotes cancer growth, invasion and metastasis. A previous study indicates that high expression of Beta2AR in HCC tissues is a biomarker for poor prognosis [10]. The 


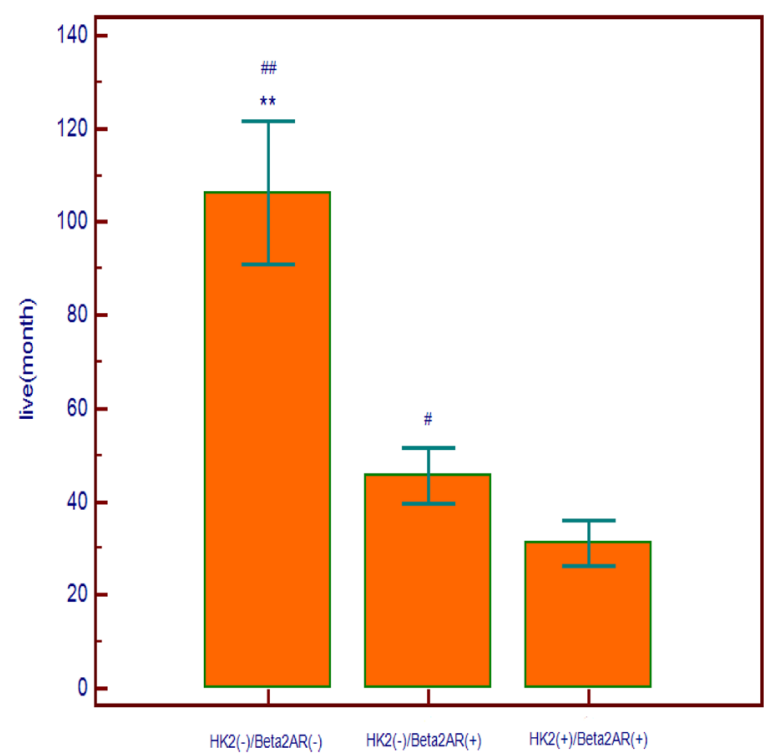

Fig. 4 The difference of live time among different groups. One-way ANOVA analysis shows that survival time of $\mathrm{HK} 2(-) /$ Beta2AR(-) is longer than that of HK2(-)/Beta2AR(+) and HK2(+)/Beta2AR(+) significantly. The survival time of HK2(-)/Beta2AR(+) is also longer than that of $\mathrm{HK} 2(+) /$ Beta2AR(+). Data are shown with mean \pm SD. \#\# $P<0.0001$ vs. HK2(+)/ Beta2(+) group, ${ }^{* *} P<0.0001$ vs. HK2(-)/Beta2(+) group, $\# P=0.001$ vs. HK2(+)/Beta2AR(+) group

Kaplan-Meier survival analysis and Cox regression analysis of our study are in consistence with the findings of this study. Our study also proves that high expression of Beta2AR in HCC is associated with large tumor size, which implies high expression Beta2AR in HCC playing an important role in tumor growth.

Glycolysis is the the key step for cellular energy metabolism, which converts glucose into pyruvate to produce adenosine triphosphate (ATP) [23]. Ten steps and corresponding enzymes participate in this process. Among these enzymes, HK is the first step enzyme converting glucose into glucose 6-phosphate, and pyruvate kinase $(\mathrm{PK})$ is the final step enzyme converting phosphoenolpyruvate into pyruvate [23]. When abundant oxygen is present, pyruvate enters tricarboxylic acid (TCA) cycle to produce ATP in mitochondria. Under hypoxia conditions, pyruvate will be converted into lactate by lactate dehydrogenase (LDH) to produce ATP. Tumor prefers the latter instead of entering the TCA cycle to produce energy, even under sufficient oxygen conditions, which is called Warburg effect [11]. HK and PK play important roles in this energy shift [24]. To date, four HK isoforms and four PK isoforms are identified in mammals [12, 25, 26]. Different from normal liver cells, HCC tissues express HK2 and PKM2 predominantly [13, 14, 27]. This isoform alteration makes cancer cells prefer aerobic glycolysis instead of aerobic oxidation [11]. Accelerated aerobic glycolysis supplies abundant energy to cancer cells for their survival, growth and metastasis [11]. HK2 participates in tumor initiation and maintenance, and HK2 depletion inhibits the neoplastic phenotype of human lung and breast cancer cells in vitro and in vivo [25]. Previous study showed that 3-bromopyruvate (3-BP), a HK2 inhibitor induced apoptosis of HCC cells via augmenting ER stress and anti-angiogenesis by protein disulfide isomerase inhibition [28]. In another study, Resveratrol (a HK2 inhibitor) also induces apoptosis of HCC cells via inhibiting aerobic glycolysis [29]. All the above evidence indicates that HK2 might be a potential therapeutic target for HCC.

Recently one study also revealed that the levels of HK2 expression in dysplastic cirrhosis and HCC was higher than that of non dysplastic cirrhosis and normal liver, which indicates that high expression of HK2 is associated with high grade of malignancy [30]. Previous studies also showed that high expression of HK2 was an independent poor prognostic biomarker for HCC [13, 14]. The results of our study are in consistence with these two survival studies. Our study also suggests that high expression of HK2 is associated with large tumor size and advanced TNM stages, which indicates that high expression of HK2 in HCC represents high levels of malignancy. High HK2 expression in HCC tissues can also be used as a biomarker for poor HCC prognosis.

Moreover, HK2 and Beta2AR are correlated in HCC development. Previous study indicates that activation of Beta2AR can promote HK2 expression, and inhibition of Beta2AR can decrease HK2 expressions in breast cancer cell lines [15]. Our study also shows positive associations between HK2 and Beta2AR in HCC tissues. Additionally, Beta2AR positive staining in $\mathrm{HCC}$ is not associated with TNM stage in our study. However, in Beta2AR positive stained samples, HK2 positive staining is associated with TNM stage. This may imply that Beta2AR increases HCC invasion and metastasis through HK2 activation. Detecting HK2 and Beta2AR simultaneously may help clinicians to evaluate the malignant status of HCC. Combination therapy of targeting $\mathrm{HK} 2$ and Beta2AR might be a promising strategy for HCC.

Combination of HK2 and Beta2AR detection also improves the predictive power for prognosis. The KaplanMeier survival analysis and Cox regression analysis of our study showed that $\mathrm{HK} 2(+) / \operatorname{Beta2AR}(+) \mathrm{HCC}$ patients had poorer prognosis compared with HK2(-)/ Beta2AR(+) and HK2(-)/Beta2AR(-) HCC patients. Detecting HK2 and Beta2AR expression in HCC simultaneously has clinical significance in prognosis prediction. However, there are some limitations of our study. Firstly, the sample number of our study is not very large, which could attenuate the statistical power. Secondly, because of the limitations of pathologic samples, only immunohistochemistry was employed in our study, other 
methods to detect HK2 and Beta2AR (Western blot and quantitative real time PCR) are needed to confirm the results of this study. Moreover, in vitro studies are also required to prove these findings. Thirdly, we were not able to calculate the score of Child Pugh due to incomplete information collection, the effect of liver function reservoir on HCC survival and Cox regression analyses could not be evaluated. Fourthly, we were unable to retrieved the recurrence information of HCC, so we did not evaluate the expression of HK2 and Beta2AR on the recurrence of HCC. Despite of the above limitations, our study will shed new light on HCC treatment and prognosis predictions.

\section{Conclusion}

In summary, Beta2AR and HK2 expression in HCC tissues is positively correlated. High expression of HK2 and beta2AR in $\mathrm{HCC}$ can predict prognosis of $\mathrm{HCC}$ patients independently and synergistically. Beta2AR might increase the grade of malignancy of $\mathrm{HCC}$ via promoting HK2 expression. Combined targeting of HK2 and Beta2AR might be a promising therapy for HCC.

\section{Abbreviations}

BCLC, Barcelona Clinic Liver Cancer algorithm; Beta2AR, Beta2-adrenergic receptor; $C T$, computed tomography scanning; GPCR, transmembrane G protein-coupled receptor; HBV, hepatitis B virus; $\mathrm{HCC}$, hepatocellular carcinoma; HCV, hepatitis C virus; HK2, Hexokinase-2; MRI, magnetic resonance images

\section{Acknowledgment}

We would like to acknowledge librarian Jiao He of the first affiliated hospital of Dalian Medical University for the retrieving of related articles. All authors declare that there is no fund provided to this research.

\section{Funding}

The authors have no support or funding to report.

\section{Availability of data and materials}

Raw data are available upon request to the corresponding author.

\section{Authors' contributions}

Conceived and designed the experiments: ZFZ, ZJD, PXL and HL. Performed the experiments: ZFZ, XSF, HC, LXW, QPZ, YL, ZGS and DY. Analyzed the data and wrote the paper: ZFZ, ZJD, PXL and HL. All authors read and approved the final manuscript as submitted.

\section{Competing interests}

The authors declare that they have no competing interests.

\section{Consent for publication}

Not applicable.

\section{Ethics approval and consent to participate}

This study was approved by Medical Ethics Committee of First Affiliated Hospital of Dalian Medical University (approval number: LCKY2015-40). Consent was obtained from all participants (alive HCC patients or relatives of deceased HCC patients).

\section{Author details}

'Department of Gastroenterology, The First Affiliated Hospital of Dalian Medical University, 116000 Dalian, Liaoning Province, China. ${ }^{2}$ Institute of Cancer Stem Cell, Dalian Medical University, 116000 Dalian, Liaoning Province, China. ${ }^{3}$ Department of Pathology, The First Affiliated Hospital of Dalian Medical University, 116000 Dalian, Liaoning Province, China.
Received: 23 October 2015 Accepted: 27 May 2016

Published online: 03 June 2016

\section{References}

1. Ferlay J, Shin HR, Bray F, Forman D, Mathers C, Parkin DM. Estimates of worldwide burden of cancer in 2008: GLOBOCAN 2008. Int I Cancer. 2010; 127(12):2893-917.

2. Forner A, Llovet JM, Bruix J. Hepatocellular carcinoma. Lancet. 2012;379: $1245-55$.

3. Cainap C, Qin S, Huang WT, Chung IJ, Pan H, Cheng Y, Kudo M, Kang YK, Chen PJ, Toh HC, Gorbunova V, Eskens FA, Qian J, McKee MD, Ricker JL, Carlson DM, El-Nowiem S. Linifanib versus Sorafenib in patients with advanced hepatocellular carcinoma: results of a randomized phase III trial. J Clin Oncol. 2015;33(2):172-9.

4. Peng $\mathrm{S}$, Zhao Y, Xu F, Jia C, Xu Y, Dai C. An updated meta-analysis of randomized controlled trials assessing the effect of sorafenib in advanced hepatocellular carcinoma. PLoS One. 2014;9(12):e112530.

5. Maudsley S, Pierce KL, Zamah AM, Miller WE, Ahn S, Daaka Y, Lefkowitz RJ Luttrell LM. The beta(2)-adrenergic receptor mediates extracellular signalregulated kinase activation via assembly of a multireceptor complex with the epidermal growth factor receptor. J Biol Chem. 2000;275:9572-80.

6. Masur K, Niggermann B, Zanker KS, Entschladen F. Norepinephrine-induced mi-gration of SW 480 colon carcinoma cells is inhibited by beta-blockers. Cancer Res. 2001:61:2866-9.

7. Weddle DL, Tithof PK, Williams M, Schuller HM. Beta-adrenergic growth regulation of human cancer cell lines derived from pancreatic ductal carcinomas. Carcinogenesis. 2001;22:473-9.

8. Kassahun WT, Guenl B, Ungemach FR, Jonas S, Abraham G. Expression and functional coupling of liver $\beta 2$-adrenoceptors in the human hepatocellular carcinoma. Pharmacology. 2012;89(5-6):313-20.

9. Chin CC, Li JM, Lee KF, Huang YC, Wang KC, Lai HC, Cheng CC, Kuo YH, Shi CS. Selective $\beta 2$-AR blockage suppresses colorectal cancer growth through regulation of EGFR-Akt/ERK1/2 signaling, G1-phase arrest, and apoptosis. J Cell Physiol. 2016;231(2):459-72.

10. Chen D, Xing W, Hong J, Wang M, Huang Y, Zhu C, Yuan Y, Zeng W. The beta2- adrenergic receptor is a potential prognostic biomarker for human hepatocellular carcinoma after curative resection. Ann Surg Oncol. 2012; 19(11):3556-65.

11. Vander Heiden MG, Cantley LC, Thompson CB. Understanding the Warburg effect: the metabolic requirements of cell proliferation. Science. 2009;324: 1029-33.

12. Wilson JE. Isozymes of mammalian hexokinase: structure, subcellular localization and metabolic function. J Exp Biol. 2003;206:2049-57.

13. Kwee SA, Hernandez B, Chan O, Wong L. Choline kinase alpha and hexokinase-2 protein expression in hepatocellular carcinoma: association with survival. PLoS One. 2012;7(10):e46591.

14. Peng SY, Lai PL, Pan HW, Hsiao LP, Hsu HC. Aberrant expression of the glycolytic enzymes aldolase B and type II hexokinase in hepatocellular carcinoma are predictive markers for advanced stage, early recurrence and poor prognosis. Oncol Rep. 2008;19(4):1045-53.

15. Kang F, Ma W, Ma X, Shao Y, Yang W, Chen X, Li L, Wang J. Propranolol inhibits glucose metabolism and 18 F-FDG uptake of breast cancer through posttranscriptional downregulation of hexokinase-2. J Nucl Med. 2014:55(3):439-45.

16. Llovet JM, Brú C, Bruix J. Prognosis of hepatocellular carcinoma: the BCLC staging classification. Semin Liver Dis. 1999;19:329-38.

17. Edmondson HA, Steiner PE. Primary carcinoma of the liver: a study of 100 cases among 48,900 necropsies. Cancer. 1954;7(3):462-503.

18. Sobin LH, Compton CC. TNM seventh edition: what's new, what's changed: communication from the International Union against Cancer and the American Joint Committee on Cancer. Cancer. 2010;116:5336-9.

19. El-Serag HB. Hepatocellular carcinoma. N Engl J Med. 2011;365:1118-27.

20. Niei B, Rotman Y, Ditah I, Lim JK. Emerging trends in hepatocellular carcinoma incidence and mortality. Hepatology. 2015;61:191-9.

21. Luo Z, Li L, Ruan B. Impact of the implementation of a vaccination strategy on hepatitis B virus infections in China over a 20-year period. Int J Infect Dis. 2012;16:e82-8.

22. Zacharias T, Wang W, Dao D, Wojciechowski H, Lee WM, Do S, Singal AG. HBV outreach programs significantly increase knowledge and vaccination rates among Asian pacific islanders. J Community Health. 2015;40:619-24. 
23. Zwerschke W, Mazurek S, Stöckl P, Hütter E, Eigenbrodt E, Jansen-Dürr $P$. Metabolic analysis of senescent human fibroblasts reveals a role for AMP in cellular senescence. Biochem J. 2003;376:403-11.

24. Li XB, Gu JD, Zhou QH. Review of aerobic glycolysis and its key enzymesnew targets for lung cancer therapy. Thorac Cancer. 2015;6(1):17-24.

25. Patra KC, Wang Q, Bhaskar PT, Miller L, Wang Z, Wheaton W, Chandel N, Laakso M, Muller WJ, Allen EL, Jha AK, Smolen GA, Clasquin MF, Robey RB, Hay N. Hexokinase 2 is required for tumor initiation and maintenance and its systemic deletion is therapeutic in mouse models of cancer. Cancer Cell. 2013;24(2):213-28.

26. Israelsen WJ, Vander Heiden MG. Pyruvate kinase: function, regulation and role in cancer. Semin Cell Dev Biol. 2015;43:43-51.

27. Chen Z, Lu X, Wang Z, Jin G, Wang Q, Chen D, Chen T, Li J, Fan J, Cong W, Gao Q, He X. Co-expression of PKM2 and TRIM35 predicts survival and recurrence in hepatocellular carcinoma. Oncotarget. 2015:6(4):2538-48.

28. Yu SJ, Yoon JH, Yang Jl, Cho EJ, Kwak MS, Jang ES, Lee JH, Kim YJ, Lee HS, Kim CY. Enhancement of hexokinase II inhibitor-induced apoptosis in hepatocellular carcinoma cells via augmenting ER stress and antiangiogenesis by protein disulfide isomerase inhibition. J Bioenerg Biomembr. 2012;44(1):101-15.

29. Dai W, Wang F, Lu J, Xia Y, He L, Chen K, Li J, Li S, Liu T, Zheng Y, Wang J, Lu W, Zhou Y, Yin Q, Abudumijiti H, Chen R, Zhang R, Zhou L, Zhou Z, Zhu R, Yang J, Wang C, Zhang H, Zhou Y, Xu L, Guo C. By reducing hexokinase 2, resveratrol induces apoptosis in HCC cells addicted to aerobic glycolysis and inhibits tumor growth in mice. Oncotarget. 2015;6(15):13703-17.

30. Guzman G, Chennuri R, Chan A, Rea B, Quintana A, Patel R, Xu PZ, Xie H, Hay N. Evidence for heightened hexokinase II immunoexpression in hepatocyte dysplasia and hepatocellular carcinoma. Dig Dis Sci. 2015;60(2): 420-6.

\section{Submit your next manuscript to BioMed Central and we will help you at every step:}

- We accept pre-submission inquiries

- Our selector tool helps you to find the most relevant journal

- We provide round the clock customer support

- Convenient online submission

- Thorough peer review

- Inclusion in PubMed and all major indexing services

- Maximum visibility for your research

Submit your manuscript at www.biomedcentral.com/submit
Biomed Central 